\title{
The River Chief System and River Pollution Control in China: A Case Study of Foshan
}

\author{
Hui Liu ${ }^{1}\left(\mathbb{D}\right.$, Yongqin David Chen ${ }^{2,3}\left(\mathbb{D}\right.$, Tao Liu ${ }^{4, *(1)}$ and Lu Lin ${ }^{5}(\mathbb{C}$ \\ 1 School of Government, Central University of Finance and Economics, Beijing 100081, China \\ 2 School of Humanities and Social Science, The Chinese University of Hong Kong, Shenzhen, \\ Shenzhen 518172, China \\ 3 Department of Geography and Resource Management, The Chinese University of Hong Kong, \\ Hong Kong 999077, China \\ 4 College of Urban and Environmental Sciences, Peking University, Beijing 100871, China \\ 5 School of Economics and Management, China University of Petroleum-Beijing, Beijing 102206, China \\ * Correspondence: liutao@pku.edu.cn; Tel.: +86-10-62764960
}

Received: 13 July 2019; Accepted: 1 August 2019; Published: 2 August 2019

\begin{abstract}
The river chief system (RCS) has been innovatively implemented in Wuxi, China since 2007 for the eutrophication control of Tai Lake. In 2016, RCS was eventually promoted throughout China to reinforce river and lake protection. The success of this new river management system is generally attributed to collaboration, accountability, and differentiation effects. This research takes Foshan in the Pearl River Delta region as a case study to examine the feasibility and weaknesses in the implementation of the RCS. Prior to the formal adoption of RCS, a coordinating organization for river improvement undertaking was established in Foshan to overcome fragmentation in water management. Compared with this practice, the new RCS can strengthen the collaboration of administrative authorities and establish a considerably sophisticated and effective management structure. Emphasis on evaluation and accountability mechanisms guarantees that management goals can be achieved. However, similar to the previous one, the new system remains a temporary management practice and its outcomes depend partially on the commitment and capability of each river chief. The imperfect evaluation and accountability mechanism also weaken its long-term effectiveness in improving river water quality. Therefore, some corresponding policy instruments are needed to ensure that RCS can be implemented smoothly.
\end{abstract}

Keywords: river chief system; collaboration effect; accountability mechanism; river pollution control

\section{Introduction}

China's rapid social and economic development in the previous four decades has brought enormous prosperity and also exploitation and pollution of the natural environment, particularly serious water pollution. The National Report on Ecology and Environmental Quality of 2017 indicated that among the 1940 water quality monitoring sites established on 423 rivers and 62 lakes, $67.9 \%$ satisfied the standards for drinking water sources (Grades I-III); $23.8 \%$ met the lower standards (Grades IV-V) for general water use in industry, recreation, or agriculture; and $8.3 \%$ were of a quality considerably below Grade V [1]. To improve the quality of the water environment, China has implemented several national projects on water pollution control and water ecosystem restoration, including the Major Science and Technology Program for Water Pollution Control and Treatment and the Water Pollution Control Action Plan by the State Council [2,3]. These projects involve numerous technological, engineering, and management measures for water pollution control, such as the construction of waste-water treatment plants and a collection pipeline network, closure of highly polluting plants, and an upgrade 
of industrial infrastructure. However, these measures are ineffective and often unsatisfactory primarily because of the fragmentation among various jurisdictional areas and engaged government agencies.

Fragmentation is one of the most commonly observed barriers in water management throughout the world [4-6]. It often occurs in several administrative areas that have hydrological connectivity or under the jurisdiction of different governing authorities with interconnected responsibilities. For water pollution control, inter-jurisdictional fragmentation results from several local governments having equal rights on the limited assimilative capacity of a shared body of water [7]. Simultaneously, intra-jurisdictional fragmentation lies in inter-agency relationship in which responsibility conflicts exist among various engaged government agencies. The former Ministry of Environmental Protection (MEP) (currently called Ministry of Ecology and Environment after the institutional reform implemented by the State Council in 2018) is given the power for pollution control and the Ministry of Water Resources (MWR) for water quantity management [8]. However, the two ministries have overlapping decision-making competencies and responsibilities for water quality management [9]. Prior to the institutional reform, MWR previously issued discharge permits and monitored pollution in rivers, whereas MEP monitored waste-water discharges at production unit outlets [10]. Although the institutional reform has adjusted the functions of the two ministries, fragmentation remains because river pollution control should be implemented on the watershed scale, which needs the collaboration of many other ministries.

The manner by which fragmentation hinders the control of water pollution is attributed to the disadvantages stemming from this barrier, including the lack of clarity of roles and responsibilities of different governmental agencies, poor inter-agency coordination and cooperation, and strong local protectionism [11]. In contrast to fragmentation, collaboration is frequently framed as a sufficient solution. Hence, various types of collaborative governance systems have been proposed as policy instruments and implemented in China to overcome the negative effects of fragmentation. In general, constituting an organization that links government agencies from the same watershed is a common practice to promote cooperation among these agencies on water-related issues; however, the current main task is on water resources allocation rather than water pollution control [12]. Although a "joint meeting system" for inter-ministry coordination has been attempted, it is not designed as an ongoing structure devoted to a single issue, thereby making it inappropriate for ongoing coordination [8]. Similar collaborative governance systems have also been adopted in other countries [5,13]. Moreover, the institutional brokerage of water quality issues was proposed as one solution, in which policy institutions emerge to forge connections between other institutions that were otherwise disconnected [14].

However, the effectiveness of collaboration in improving water management efficiency is not a certainty [15]. Numerous factors preclude collaboration among departments, including bureaucracy, inconsistencies of approach by individual decision makers, communication difficulties, and conflicting policy objectives [16]. Individual officials' personal perceptions of responsibilities for environmental decisions are also an important factor [17]. Cook (2014) summarized four elements of governance patterns to determine whether they are cooperative, conflictual or reactive and whether the outcomes are innovative, stagnant, or piecemeal: An institution that facilitates coordination, agreement on roles and responsibilities, agreement on the issue management plan, and the scope of the issue [4]. These factors are important concerns in analyzing whether a new policy instrument on water management can achieve its management goals efficiently and effectively.

The river chief system (RCS) is a new policy instrument in China that attempts to overcome fragmentation in water management and improve water quality effectively. RCS was first taken as an innovative policy instrument by the local government of Wuxi Municipality, Jiangsu Province in 2007 to fully implement water pollution control [18]. Thereafter, RCS was imitated and implemented in the entire Jiangsu Province, followed by Yunnan and Henan, and other provinces [19]. Given the effectiveness and success of RCS in river water quality management, this system has been approved by the central government and promoted throughout China in 2016 to reinforce river and lake protection. In this sense, RCS can be considered a successful local-level innovation of policy instrument and 
its promotion follows a parallel, bottom-up and eventually top-down routine, which is similar to many local institutional innovations in post-reform China. However, the promotion of this policy instrument in the entire country faces uncertainties in terms of efficiency owing to diversified natural, socioeconomic, and political circumstances. To rigorously examine the feasibility and barriers in the adoption and implementation of RCS, this study first reviews the current development and achievements of RCS and the explanations on why it can come into effect for water quality control. Thereafter, Foshan Municipality in Guangdong Province is taken as a case study because it has a long history of establishing a comprehensive office for river water pollution control since 2003. Lastly, comparative studies on RCS and the preceding management practices are conducted to analyze whether RCS can be efficient and effective for water quality control in Foshan.

\section{Development and Achievements of RCS}

\subsection{Local-Level Governance Innovation to Combat Water Pollution}

The innovation of RCS in Wuxi Municipality was implemented after a drinking water crisis resulting from blue algae bloom and eutrophication in Tai Lake caused by the seriously polluted rivers flowing into the lake with high concentrations of nitrogen and phosphorus [20,21]. Although the water pollution control of inflowing rivers was imperative, the pollution control management system appeared to break down owing to the high-density river network and rapid socioeconomic development. This failure was attributed to unclear pollution control goals, incomplete pollution sources, and lack of coordination among government agencies. Therefore, RCS was proposed to fully implement water pollution control.

The government document titled "River Cross Section Water Quality Control Goals and Assessment Method in Wuxi (trial version)" was released in 2007 as guide to combat water pollution after the drinking water crisis. The document provided the local chief executive responsibility system for rivers (and other water bodies) and indicated that the water quality monitoring results of river cross-sections would be included in the government performance evaluations of Party and Government heads. This system reflects the typical features of China's administrative regime, that is, the immense power and weighty responsibility of chief commanders in the majority of local affairs. According to this system, those who do not turn in reports or submit late or false reports on water quality monitoring results would be held accountable [22]. Thus, the concerned officials had been given the new title of "river chief" and the aforementioned document was considered the origin of RCS. Thereafter, the water quality monitoring results of 79 river cross-sections were included in the government performance evaluation; a rate increase from $53.2 \%$ to $71.1 \%$ in satisfying the water quality goals was obtained after one year [23]. Given the grade-based system of water quality assessment, this increase did not indicate the accurate degree of water quality improvement in a certain river. However, such an improvement demonstrated the effectiveness of RCS on water pollution control as a whole, thereby resulting in the promotion of RCS in other regions.

\subsection{Development of RCS}

RCS places the main responsibility of river water pollution control on the local government heads. In local practices throughout China, a leading group often led by Party and government heads is organized. These heads are also the river chiefs of the rivers flowing in their respective jurisdictional areas, while some specific river chiefs may be heads of government agencies. The guideline titled "On fully implementing RCS" by the Communist Party of China Central Committee and the State Council published in 2016 provided clear statements on the official ranks of river chiefs. A four-level organizational form of RCS is constituted. In particular, the heads of provincial regions will be the general chiefs responsible for all rivers and lakes in the region, while government senior officials are appointed as river chiefs at the provincial, city, county, and township levels (Figure 1). River chiefs take full responsibility for all management and protection undertakings of their corresponding 
rivers, including water resource protection, water pollution control, water ecological restoration, law enforcement, and monitoring. Among these responsibilities, water pollution control is currently given the highest priority.

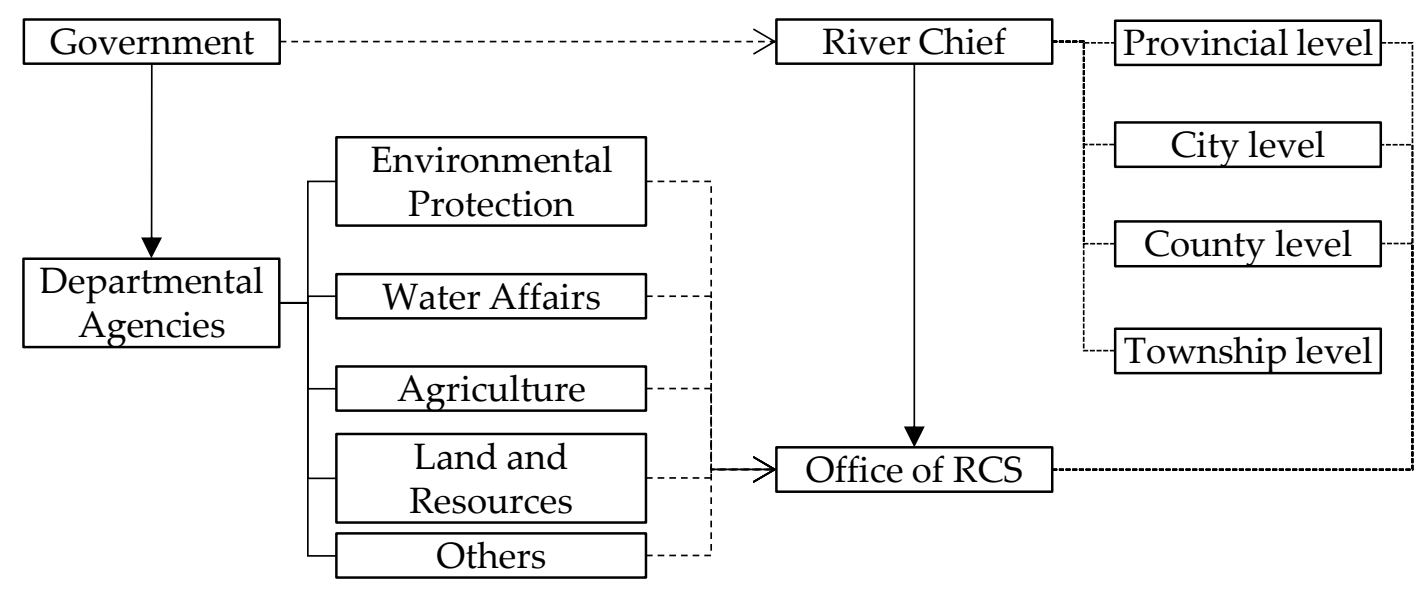

Figure 1. Correspondence between the administrative structure and river chief system (RCS). (Dotted line with an arrow shows the correspondence. The river chiefs of different levels should be senior government officials on the corresponding levels. The office of RCS consists of department agencies on the corresponding levels. Line with an arrow shows the flow of authority.).

An RCS office, which is affiliated to the leading group of RCS, is also established to lead in the practical affairs (Figure 1). The leading department or person can be the departments in charge of environmental protection or water affairs or even government heads with specific duties, depending on the main tasks in this region [24]. The environmental protection department often plays the leading role in water pollution control. Given that river pollution control needs a series of measures promulgated by various department agencies in charge of land use, agriculture, industries etc. on the entire watershed scale [25], the RCS office consists of officials from various department agencies engaged in the promotion of inter-agency collaboration.

A series of auxiliary systems on collaboration, evaluation, and supervision is established to enforce the implementation of RCS. The collaboration system ensures that the engaged department agencies can have smooth communication related to information-sharing and effectively play their respective roles in water pollution control. The strictness of the evaluation system determines whether RCS can be effective. For example, the evaluation group in Wuxi is led by the vice-mayor and composed of representatives from all the engaged government agencies with four subgroups: (1) Planning demonstration, (2) water quality monitoring, (3) measures promotion, and (4) long-term management; the water quality of the river cross-section is included in the evaluation system as a condition for cadre selection and appointment and a "one vote veto" practice is adopted [22]. In the supervision system, supervision from the leading group is conducted periodically and briefing notifications on supervision progress are formed. Public supervision is likewise carried forward. The list of river chiefs is announced through media and detailed information, such as responsibilities, goals, and contact numbers, is also posted on billboards along the rivers. The civil river chiefs, who are selected from various walks of life and demonstrate great interest in river protection in Hangzhou, have played important roles similar to the government river chiefs [26].

\subsection{Achievements and Explanations}

Water quality improvement is of high concern as an achievement of RCS. However, only a few reports on this issue can be found in online news and journal articles. These reports have shown encouraging achievements of significant improvement in water quality. For example, the rates of satisfying the water quality goals were $55.3 \%, 76.8 \%, 90.9 \%, 95 \%$, and $96 \%$ for $2010,2011,2012,2013$, 
and 2014, respectively, thereby showing an evident increase after the implementation of RCS in the Sancha River watershed in Guizhou [27]. Among the 36 river cross-sections monitored in RCS in Qujing, Yunnan Province, the rate of satisfying the water quality goals increased from 78.9\% in 2011 to $90.3 \%$ in 2015 [28], while the rate maintained above 70\% from 2011 to 2016 in Wuxi [29,30]. Similar to our previous comments on water quality data, although these numbers cannot accurately reflect the absolute decrease of water pollution concentration, they do demonstrate the evident effectiveness of RCS on water quality improvements. Apart from the concrete data on water quality improvement, other achievements have been demonstrated in the outcomes of RCS' role in preventing water pollution.

The first outcome is the strengthened collaboration among various department agencies, which is the most important and evident result of RCS. The river chief, who is the government or party head; and the RCS office, which consists of various engaged department agencies, guarantee that all administrative resources and power can be maximized. Given the diversity and complexity of water pollution sources, pollution prevention requires effective coordination among various government agencies, including those involved in environmental protection, water affairs, agriculture, urban construction, and land and resources. RCS does not change the primary assignment of responsibilities among these agencies but provides a platform, under the centralized arrangement of local government, for them to coordinate in information sharing, program development, and implementation [31]. The establishment and operation of this platform rely immensely on the role played by the river chief. In particular, the river chief can considerably balance the original primary responsibilities and water quality improvement tasks of departmental leaders through the local political systems of performance assessment and promotion under their charge.

Accountability is another aspect that distinguishes RCS from current conventional management systems. The government has invested substantial energy in the water quality monitoring of every section of various rivers. Whether the water quality satisfies the pre-set goals is included as one aspect of an official's government performance evaluation system. Given that a senior government official is appointed as river chief, such a designation ensures that the responsibility of river protection, including water pollution control, is completely assumed by a specific person at a high level in the local government [32] rather than merely by environmental protection bureau or spreading across several agencies, which often creates difficulties in accountability. Moreover, the accountability effect would prompt the river chief to maximize monetary and human resources within his powers to combat river pollution. Although the duty assignment of officials did not change, water quality protection becomes nearly equally important with economic development, thereby directly and substantially enhancing the position of water pollution control in policy-making.

Lastly, RCS promotes a differentiation effect in river protection. The main characteristics of rivers and the challenges they face are usually different. Even for water pollution control, the distinguished quantity, composition, and spatial distribution of pollution sources and specific natural conditions of each river requires targeted pollution control measures. For the majority of rivers, particularly small streams, such a basic information as water quality and pollution sources was previously lacking, thereby necessitating the implementation of generalized pollution control measures. Under RCS, river chiefs are required to substantially know such information, thereby leading to the conduct of detailed investigations of rivers. The "one river, one file" and "one river, one plan" systems are also established in some regions to promote differentiated measures on each river [24].

\section{Case Study of Foshan: Management Efforts in River Pollution Control}

\subsection{Study Area}

Foshan is located in Guangdong Province and is one of the nine cities in the Pearl River Delta region. The mainstreams of Xijiang and Beijiang in the Pearl River system meet in this locality and form a typical river network area with a high river density. Apart from mainstreams, several waterways and tributaries also flow through the city, together with thousands of small streams (locally called 
"Chong") connecting them (Figure 2; small streams are not shown). The Pearl River Delta region has been a pioneer in carrying out China's reform and opening-up policy and Foshan, which is a city with a long development history, is one of the most developed in this region.

China's rapid and continuous economic growth has brought immense wealth but serious effects on the environment as well. Factories and population discharge a huge quantity of industrial wastewater and domestic sewage, but wastewater treatment facilities fail to keep pace with the discharge growth, thereby leading to notoriously poor quality of water environment. Even though the Pearl River mainstream maintains an acceptable water quality, the tributaries and some inner rivers (locally named "Nei He Chong") have considerably worse water quality than the goals set. The Foshan waterway (locally called Fenjiang River) flows through the downtown area of Foshan and is considered the "mother river" of the city. The water quality of the Foshan waterway deteriorated because of the massive water pollutants exceeding the environmental capacity, specifically for nutrients from domestic sewage (Figure 3). Moreover, the bi-directional river flows during flooding and ebbing caused by the natural hydrological characteristic as a tidal river and the water gates built at the confluences of rivers make the river pollution control substantially complex and difficult.

Various measures have been formulated on the Foshan waterway for river pollution control and water quality restoration. Apart from engineering measures, management measures to promote the coordination among department agencies have also been attempted in recent years.

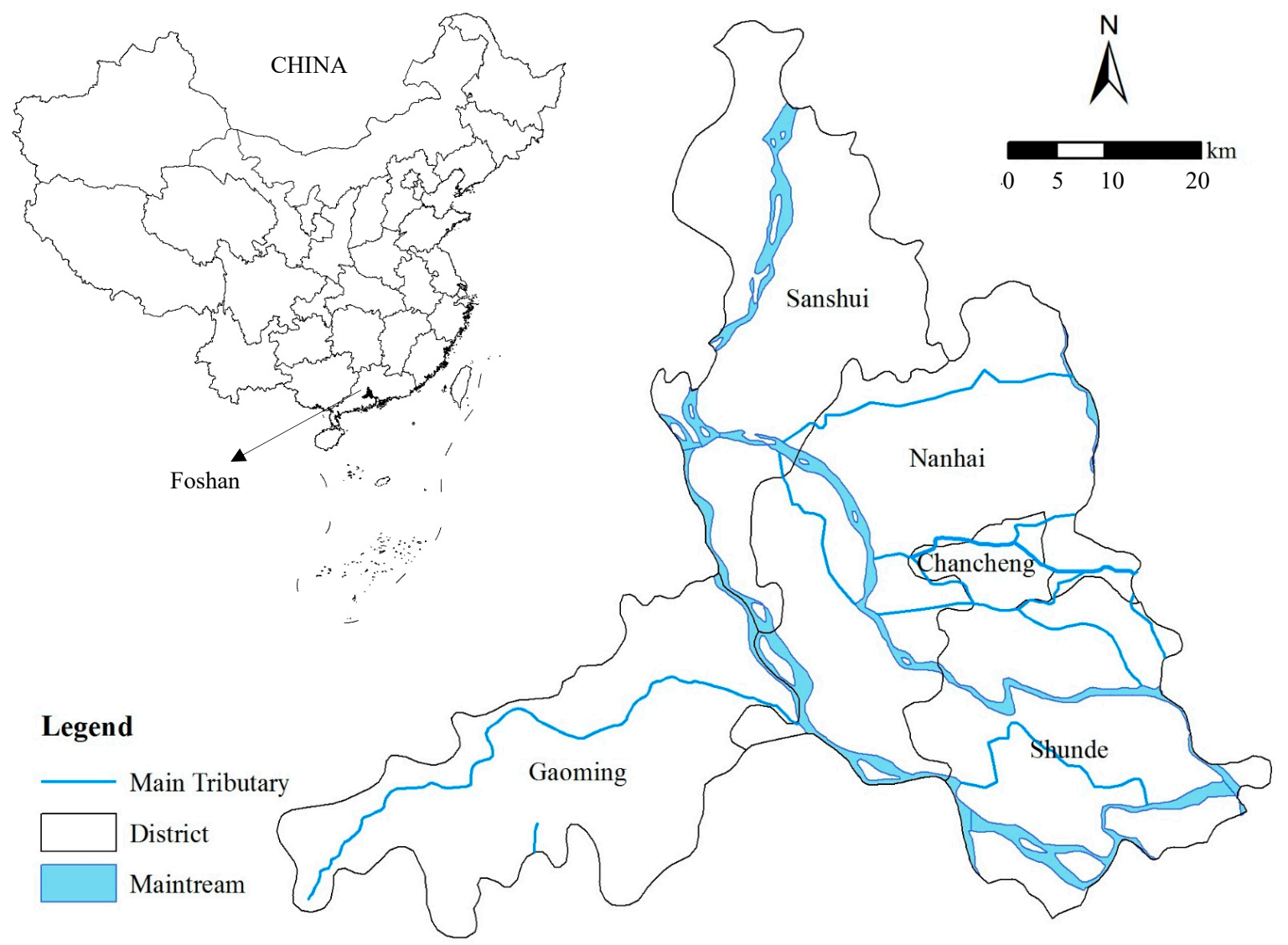

Figure 2. Location and river system of Foshan Municipality. 


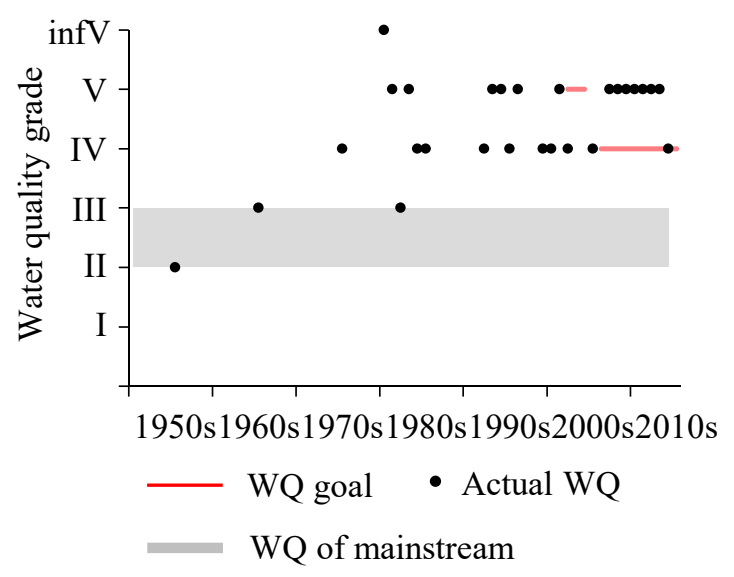

(a)

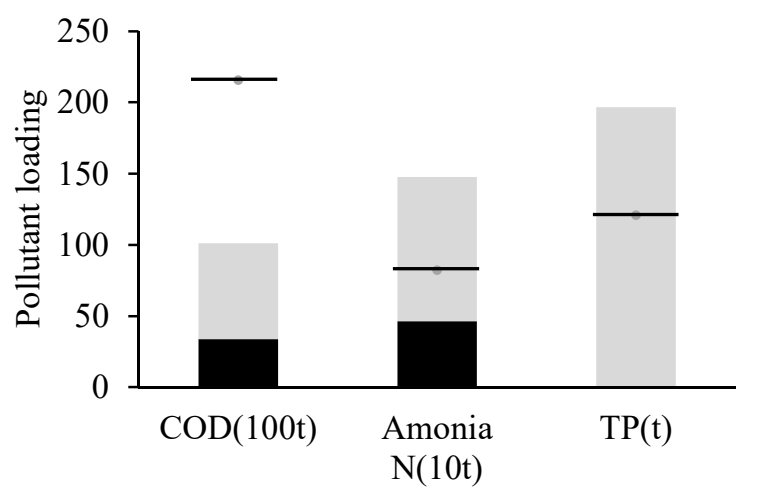

- Industrial Domestic $\longrightarrow$ Capacity

Figure 3. (a) Historic records of water quality of the Foshan waterway. Water quality is assessed on the bases of six grades with functions of drinking water sources (Grades I to III); general water use in industry, recreation, or agriculture (Grades IV-V); and harmful water for direct contact (Grade infV). (Source: Foshan Yearbook 1993-2015). (b) Water pollution source and environmental capacity. The unit " $\mathrm{t}$ " means ton. (Source: Study on work plan of continuous and further improvement of the Foshan waterway [33]).

\subsection{Previous Pilots Conducted in Foshan}

The establishment of a comprehensive office to consolidate the powers of various department agencies for river water pollution control was recognized as an important management measure by the local government of Foshan in 2003. At that time, Foshan was bidding for the title of "Model City for Environmental Protection" and improving water quality of the Foshan waterway was proposed as a necessary condition. Thereafter, an office in charge of the water environment aspect in the bidding was established and affiliated to the Environmental Protection Bureau.

The continuously deteriorating river water quality aroused the government's attention again in 2007 and the idea of comprehensive restoration on the entire watershed scale was adopted by the leaders in charge at that time. In 2008, a headquarter was established to achieve the goal of "Cleaning-Up the River in Three Years". This headquarter was led by the mayor and composed of district heads and directors of 15 bureaus (i.e., Economy and Trade, Finance, Land Resource, Urban Construction, Transportation, Water Conservancy, Culture and News, State-owned Asset, Environmental Protection, Tourism, Urban Management, Urban Planning, Public Works, Waterway, and Maritime Affairs). These bureaus took charge of affairs on river improvement, in which such pollution control measures as the closure and relocation of highly polluting plants and industrial pollution supervision are the most important. Simultaneously, the Fenjiang River Comprehensive Restoration Office (FRCRO) was established under the aforementioned headquarter and positioned as a coordinating organization, which consists of vice-heads and vice-directors of the aforementioned districts and bureaus. Professional and technical staff members were also transferred from these bureaus to work in FRCRO on the river restoration endeavor.

The direct engagement of the mayor and directors concerned enabled the concentration of the relevant authorities, guaranteed efficiency of the restoration work, and achieved remarkable outcomes. However, the attempt to promote the normalization of such an institution encountered barriers. Although FRCRO was originally set to be equal to other bureaus to smoothly carry out its mandate, the limitation in authorized size constrained its establishment. Thus, the office was organized under the Water Affairs Bureau but independent from the latter's business. The new unit of municipal administration in 2010 ceased support to such an institution by weakening the concentrated authorities, returning the majority to their former departments, and revoking the office's supervision power. 
In 2013, the office was dissolved and reorganized to become one division of the Environmental Protection Bureau.

Public participation and supervision was also promoted during this period. Extensive news and reports were published in the Foshan Daily and Government websites, where the overview and progress of the river restoration were introduced. Observers, reviewers, and supervisors were recruited from the general public to follow up on the changes in Fenjiang River. A discussion platform was also started in a local Internet forum. Apart from the positive reports from observers and reviewers, posts focusing on unsatisfactory river conditions and illegal wastewater discharge constantly received active responses from the public and government officials.

\subsection{Implementation of $R C S$}

During the cleaning-up campaign phase, RCS was introduced and implemented with the appointment of the vice-mayor, who was also the vice-leader of the headquarter, as the river chief of the Foshan waterway. The vice-heads of the two districts where the river flows were appointed as section chief, while the heads of the seven sub-district offices were called "chong chief" in-charge of the 16 inner rivers flowing in their respective jurisdictions. This practice aimed to clean the small tributaries, thereby supporting the river clean-up goal. However, the inexplicit goal and responsibility of these chiefs and the lack of an accountability system have resulted in the incomplete implementation of the system.

Since 2014, Foshan has exerted substantial effort to promote RCS again. The implementation of RCS covers the entire city and 227 small streams would have their river chiefs. All river chiefs are heads of districts, sub-districts, or townships, depending on the levels of the rivers. An environmental protection committee, led by the government and Party heads, is currently acting as the leading group of RCS at the city level. The river chiefs should assume five-step responsibilities to control river pollution: Pollution symptom description, pollution sources analysis, pollution control scheme making, pollution control measures promotion, and achieving water quality goals.

The evaluation system consists of water quality and project progress. Given that the responsibilities in river pollution control are divided into the aforementioned five steps, the evaluation system is quantifiable, measurable, and can provide clear evaluation results. The evaluation is conducted quarterly and annually to rank the water quality of each district and town. The results are part of the environmental protection responsibility evaluation system of officials, which is also an important evidence of the comprehensive evaluation of government performance of officials. Moreover, the river chiefs of districts or towns with low water quality ranking and has no progress in three months are asked to provide a written self-criticism to be presented to the environmental protection committee and the public. Meanwhile, the "one vote veto" practice is also adopted on the river chiefs whose rivers have no improvement in water quality in the previous year. Economic incentive is also designed to link with the river improvement projects. A one million RMB Yuan deposit is given once a river is in the key supervision list and can only be returned if the improvement work is completed and approved to be unlisted on schedule. Otherwise, the deposit is withheld as a fine and placed into a special account for environmental protection.

Apart from official supervision from the environmental protection committee, the water quality results and ranking of each river are publicized on the official website of the Environmental Protection Bureau every month for information disclosure and public supervision. Billboards that show information on the river chiefs are set along the river. Supervisors living or working near rivers are hired to monitor these bodies of water. 


\section{Achievements and Weaknesses in Implementation of RCS}

\subsection{Achievements in River Pollution Control}

The pollution control effort from 2008 to 2010 had reduced the pollutant loads discharged into the river by closing nearly 100 highly polluting plants, most of which are textile and dyeing plants. Compared with 2008, the concentration of the dissolved oxygen in 2010 increased by 124\%, while that of COD, ammonia N, and TP decreased by $11 \%, 40 \%$, and $20 \%$, respectively [34]. Although the water quality goal has yet to be achieved, the river is no longer black and malodorous. Given that the concern was mainly focused on the Foshan waterway, no evident changes in the small inner rivers were observed.

Since the full implementation of RCS in Foshan in 2014, the focus on water quality improvement of inner rivers has brought significant changes. Monthly water quality monitoring results publicized on the official website of the Foshan Environmental Protection Bureau have shown that among the first 42 rivers under charge of river chiefs, the rate of satisfying Grade $\mathrm{V}$ requirements has increased from approximately $40 \%$ to $70 \%$ (Figure 4). Compared with the first phase, constituting a full-fledged and sophisticated river chief system on the entire city scale has resulted in an overall improvement of river water quality. The monthly comprehensive pollution index (CPI) changes of the Nanhai section of the Southeast Inner River show water quality improvement from 2016 to 2017 (Figure 5). The main pollutants are ammonia N and TP. Despite the existence of the legacy effect of pollution, the water quality of the inner rivers in Foshan fluctuates substantially and may leap between satisfying and unsatisfying the requirements among months. The possible reason is that Foshan is located at the estuary area of Zhujiang River and the large flow quantities during the rainy season can offset the legacy effect.

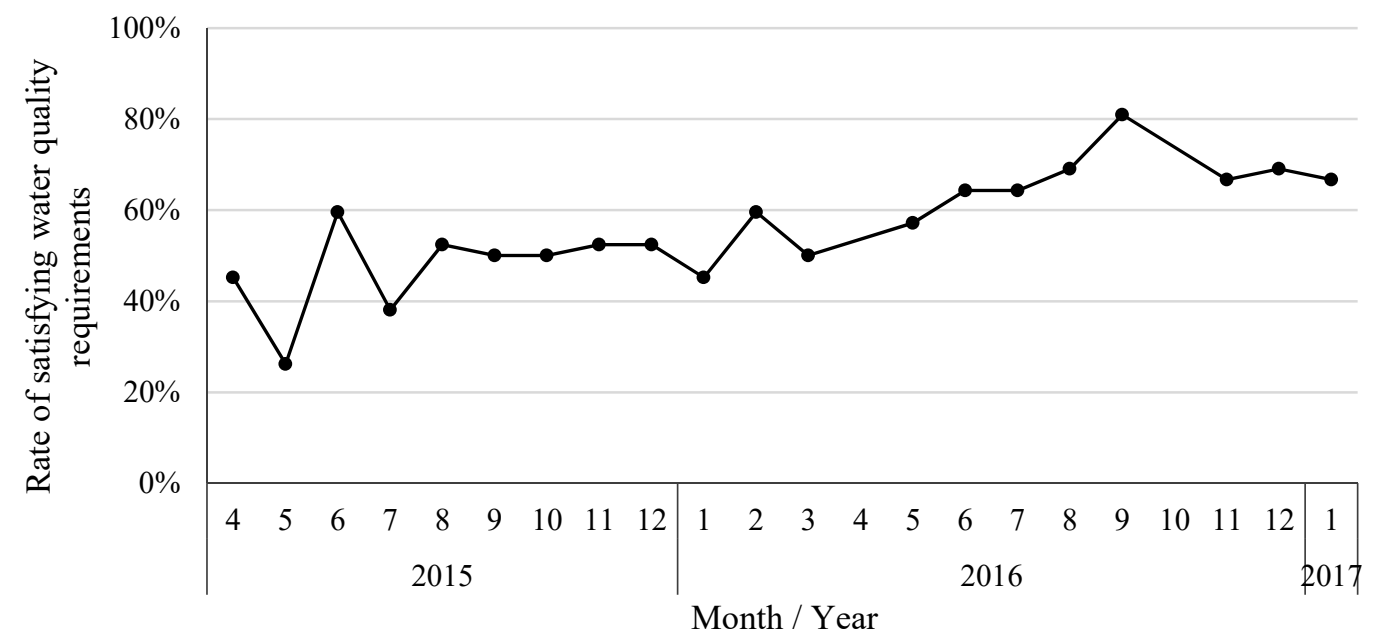

Figure 4. Rate of the first 42 rivers satisfying the Grade V requirements under charge of the river chiefs (Source: Official website of Foshan Environmental Protection Bureau). 


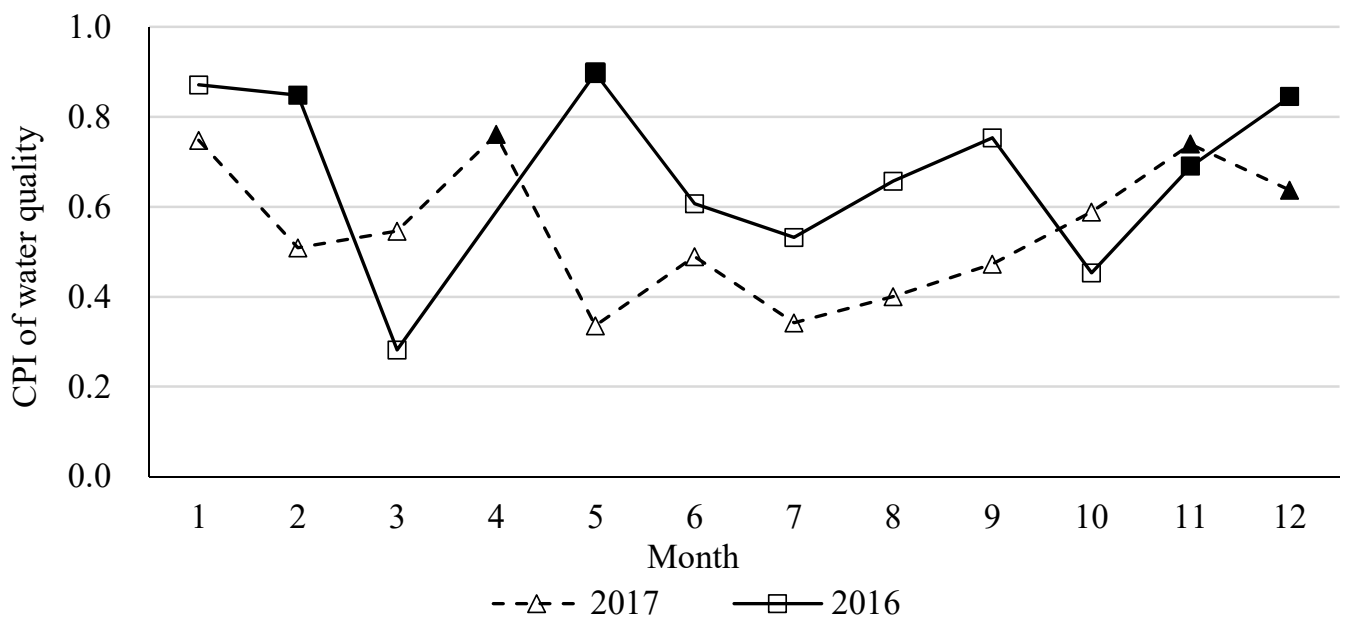

Figure 5. Monthly comprehensive pollution index (CPI) of the Nanhai section of the Southeast Inner River in 2016-2017. The filled triangle or square means the water quality does not satisfy the requirements in this month. CPI is calculated as the average ratios of the monitored and required concentrations of the five indicators (i.e., COD, BOD, ammonia N, TP, and permanganate indexes). Lower values mean better water quality, but the value of CPI does not strictly correspond to whether it satisfies the water quality requirements. (Source: Official website of Foshan Environmental Protection Bureau).

\subsection{Comparisons between the Two Phases of River Pollution Control}

During the two phases of river pollution control, there both exist a leading organization coordinating various engaged department agencies and district governments. The former is the headquarter for the Fenjiang river comprehensive restoration, whereas the latter is the environmental protection committee. They are organized at the city level and led by municipal government heads, thereby ensuring that all government powers can be maximized for river pollution control. Comparatively, the latter has strengthened the effectiveness of coordination through the river chiefs at different levels.

Moreover, supervision from the public is considered. To promote public supervision, efficient and effective information disclosure is essential for the public to know and gain interest in the undertaking. Such information as river water quality, improvement work progress, and the means for the public to inquire and report illegal behaviors is publicized through various forms of media. Billboards showing the contact information of the river chief concerned can assist the public to directly communicate with this official, thereby enhancing the efficiency of communication and problem-solving.

Accountability effect is the key characteristic of RCS. The river pollution control responsibility of each river is imposed on a certain official. Accordingly, the progress in water quality improvement is an important evidence for the government performance evaluation of the concerned official. Therefore, the river chief is pushed to formulate a targeted plan that can efficiently facilitate the achievement of the evaluation requirement. Moreover, the one-million deposit also increases the weight of pollution control in policy-making compared with the tax revenue from highly polluting plants. The accountability effect is important in explaining why a significant increase in the rate of satisfying Grade V of rivers has been obtained since 2015 in Foshan.

\subsection{Weaknesses in the Implementation of RCS}

RCS has made progress in reinforcing collaboration and accountability in river pollution control, thereby obtaining some successes in improving river water quality. However, weaknesses remain in several aspects, which have already appeared in its implementation in Foshan, thereby impairing the effect and limiting this system's promotion in other environmental protection issues.

A leading organization at a high level is important in promoting collaboration among department agencies and districts. In Foshan's practice, the leading organizations of the two phases are governance innovation by the local government, thereby implying that their important roles may be weakened or 
even lost when government transition and replacement occur. The campaign-style governance can immediately yield the necessary effects, particularly in terms of effective pollution control [35]. However, inconsistency in implementation can cause a high risk of relapse. The position change of FRCRO as an ending sign of the first phase's river pollution control is a good proof. Although the guideline titled "On fully implementing RCS" by the Communist Party of China Central Committee and the State Council emphasizes the government head's responsibility of river protection, long-term implementation requires institutional support from organizational restructuring and change in evaluation criteria.

RCS places the responsibility of river pollution control on a specific person, who stimulates the enthusiasm of river chiefs to conduct active practices for river water quality improvement. However, the improvement depends heavily on the personal abilities of the river chiefs [36]. These abilities are influenced by many factors, including personal knowledge of pollution control and personal subjective initiative. Therefore, the "rule of man" mode is flexible when facing diversified river conditions but not constant in efficiency. For example, township heads had better performance than district heads from April 2015 to March 2016 when RCS was applied on the first 42 rivers (Figure 6). Two possible reasons can explain this situation. On the one hand, the township heads in charge of a smaller jurisdiction area are more familiar with the local conditions, thereby enabling them to make more targeted pollution control plan and implement it fully. On the other hand, the average number of rivers under the district heads was 2.25, whereas that of township heads was 1 . This situation placed a heavy burden on the district heads, thereby decreasing their effectiveness. This can also be proven in the period from April 2016 to January 2017, when 90 new rivers were included in RCS. The average number of rivers under township heads increased to 3.6 and the rate of satisfying Grade V requirements decreased significantly and was even lower than that of the district heads (Figure 6).

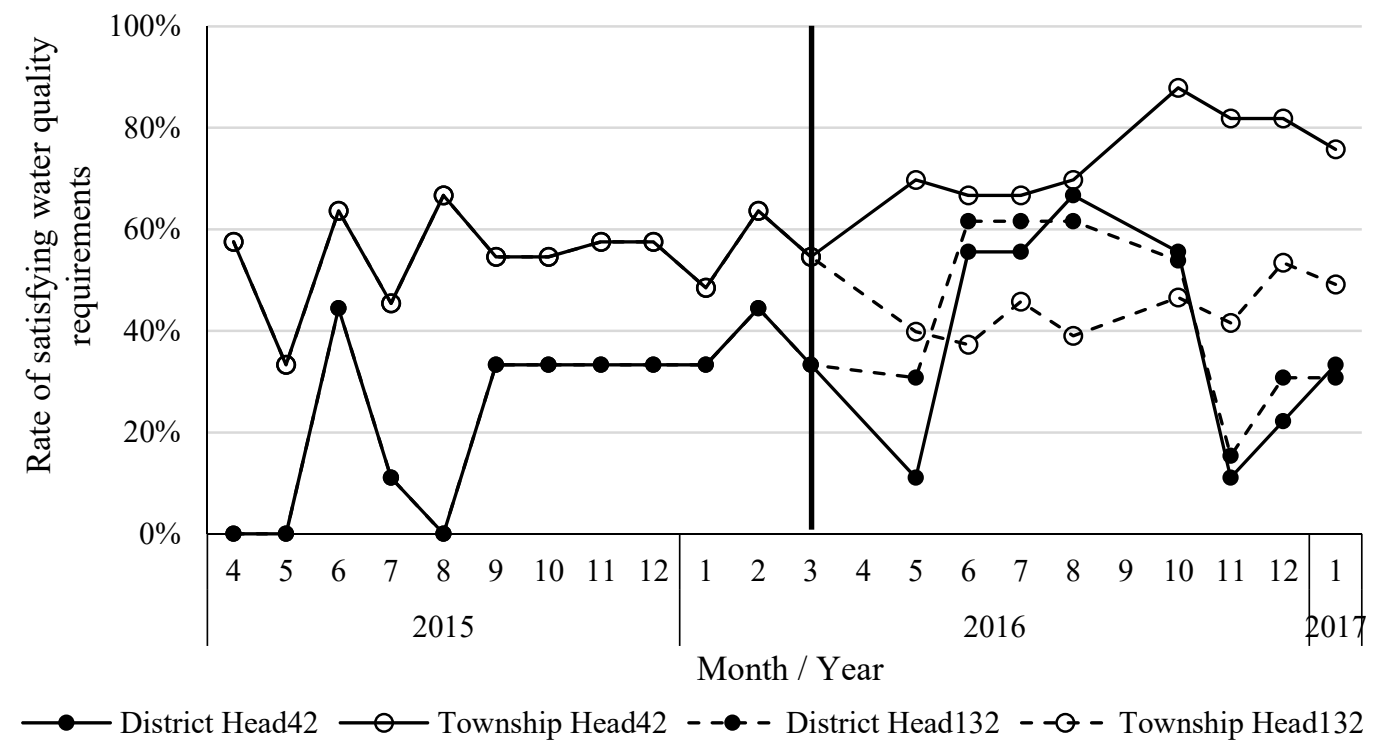

Figure 6. Rate of satisfying the Grade V requirements for the first 42 rivers and later 132 rivers (90 rivers have been included since March 2016) under the river chiefs at the district and township levels. (Source: Official website of Foshan Environmental Protection Bureau).

Although we emphasized that the evaluation and accountability mechanisms are key features guaranteeing that river chiefs take their responsibilities actively, there exist many problems in the current evaluation and accountability mechanism. The weights of the two aspects of water quality and project progress in the evaluation system in Foshan should be further deliberated and considered. Given a high weight of project progress, the majority of the rivers can obtain good marks in the evaluation; thus, river chiefs are oriented to aggressively implement restoration projects without sufficient considering whether the projects can bring real improvement in water quality [32]. Even if water quality is the only indicator in evaluation, water quality monitoring processes have several 
uncertainties. The water quality of the inner rivers connecting with the large tributaries is heavily influenced through the water gate control in Foshan. At present, the monitoring frequency is limited to only once every month and the variation in monitoring time can lead to significant change in monitoring results.

River processes vary geographically and each river has its own difficulties in water quality improvement. Accordingly, finding a completely fair method to evaluate the performance of river chiefs is difficult. The establishment of water quality goals is often controversial as well. The goals have changed in Foshan since January 2017, with some pollutant concentrations of several rivers above the Grade V requirements. The changes will certainly influence evaluation results. Therefore, goal setting is relatively arbitrary and cannot be a sound basis for evaluation without a total water pollution control plan made as a supporting system to provide detailed water quality goals requirements of each river cross section [37]. Accountability is constantly difficult to implement strictly under the current political circumstances [38]. Hence, no accountability case has yet to be published despite the increasing number of river chiefs being appointed similar to other cities.

\section{Conclusions}

RCS is a local governance innovation that aims to effectively and efficiently improve river water quality. This system has demonstrated its effectiveness and some success, thereby leading to its widespread implementation throughout China. The core component of RCS is appointing Government and Party heads at different levels as river chiefs to take charge of the rivers in their jurisdictional areas, together with officials from all engaged department agencies forming an office to conduct practical affairs. Such a personnel placement imposes the responsibilities of river pollution control on a specific person, who has the power and motivation to collaborate with all department agencies. Apart from the collaboration effect, accountability and differentiation effects are two other explanations for the success of RCS.

The case study of Foshan shows that, compared with the previous pilots of establishing FRCRO as a coordination organization led by the mayor, RCS has strengthened the collaboration effect through the appointment of district and township heads as river chiefs and constituted an evaluation system consisting of water quality and project progress and accountability system from the political, social, and economic aspects, thereby ensuring that each river chief fully takes their responsibilities. The increased rate of satisfying water quality goals of rivers demonstrates that the implementation of RCS in Foshan is successful in river pollution control. However, inconsistent implementation, overemphasis on the rule of man, and imperfect evaluation and accountability systems do impose constraints on the effectiveness and efficiency of RCS. Such policies as constant institutional arrangement and establishment of corresponding systems on goals setting are needed to promote the long-term implementation and success of RCS.

Author Contributions: For this work H.L. and Y.D.C. developed the conceptual foundation; H.L. collected the data; H.L. and T.L. analyzed the data; H.L. and T.L. wrote the initial manuscript; Y.D.C. and L.L. contributed to review and editing work; T.L. contributed to funding acquisition.

Funding: This research was completed with support from National Natural Science Foundation of China (41801132) and the PEAK Urban program, funded by UKRI's Global Challenge Research Fund, Grant Ref: ES/P011055/1.

Acknowledgments: Thanks to Officials of Environmental Protection Bureau of Foshan Municipality for their support and collaborations during the investigation work.

Conflicts of Interest: The authors declare no conflicts of interest. The funders had no role in the design of the study; in the collection, analyses, or interpretation of data; in the writing of the manuscript, or in the decision to publish the results.

\section{References}

1. National Report on Ecology and Environmental Quality of 2017. Available online: http://www.mee.gov.cn/ hjzl/zghjzkgb/lnzghjzkgb/201805/P020180531534645032372.pdf (accessed on 5 December 2018). 
2. MEP. Introductions on Major Science and Technology Program for Water Pollution Control and Treatment. Available online: http://nwpcp.mep.gov.cn/zxgk/201308/t20130823_258572.html (accessed on 25 July 2019).

3. State Council. State Council Notice on Water Pollution Control Action Plan. Available online: http://www.gov.cn/zhengce/content/2015-04/16/content_9613.htm (accessed on 25 July 2019).

4. Cook, C.L. Governing jurisdictional fragmentation: Tracing patterns of water governance in Ontario, Canada. Geoforum 2014, 56, 192-200. [CrossRef]

5. Nava, L.F.; Sandoval-Solis, S. Multi-tiered Governance of the Rio Grande/Bravo Basin: The fragmented water resources management model of the United States and Mexico. Int. J. Water Gov. 2014, 2, 85-106. [CrossRef]

6. Wardropper, C.B.; Chang, C.; Rissman, A.R. Fragmented water quality governance: Constraints to spatial targeting for nutrient reduction in a Midwestern USA watershed. Landsc. Urban Plan. 2015, 137, 64-75. [CrossRef]

7. Song, G.J.; Han, D.M. Advising institutional reform of water pollution management system in China. Adm. Reform. 2012, 13-17. [CrossRef]

8. Ongley, E.D.; Wang, X.J. Transjurisdictional water pollution management in China: The legal and institutional framework. Water Int. 2004, 29, 270-281. [CrossRef]

9. Song, X.; Ravesteijn, W.; Frostell, B.; Wennersten, R. Managing water resources for sustainable development: The case of integrated river basin management in China. Water Sci. Technol. 2010, 61, 499-506. [CrossRef] [PubMed]

10. Da Silveira, A.R.; Richards, K.S. The link between polycentrism and adaptive capacity in river basin governance systems: Insights from the River Rhine and the Zhujiang (Pearl River) Basin. Ann. Assoc. Am. Geogr. 2013, 103, 319-329. [CrossRef]

11. Rui, M. China's Fragmented Political Structure and the Effect on Environmental Policy Enforcement-On the Water Pollution Control in the Tributaries in the Three Gorges Reservoir Area. Master's Thesis, University of Southern California, Los Angeles, CA, USA, August 2008.

12. Wang, Q.G.; Gu, G.; Higano, Y. Toward integrated environmental management for challenges in water environmental protection of Lake Taihu basin in China. Environ. Manag. 2006, 37, 579-588. [CrossRef]

13. Chou, L.M. The cleaning of Singapore River and the Kallang Basin: Approaches, methods, investments and benefits. Ocean Coast. Manag. 1998, 38, 133-145. [CrossRef]

14. Jasny, L.; Lubell, M. Brokering Institutions and Fragmentation in Water Governance. In Proceedings of the American Sociological Association Annual Meeting, San Francisco, CA, USA, 15 August 2014.

15. Cook, C.L. Putting the Pieces Together: Tracing Fragmentation in Ontario Water Governance. Ph.D. Thesis, University of British Columbia, Vancouver, BC, Canada, December 2011.

16. Yu, Y. Role of institutional capacity on river pollution control and management: A case comparison between the Pearl River on Guangzhou Section and the River Thames on London Section. Trop. Geogr. 2012, 32, $22-31$. [CrossRef]

17. Lo, C.W.H.; Fryxell, G.E.; Wong, W. Effective regulations with little effect? The antecedents of the perceptions of environmental officials on enforcement effectiveness in China. Environ. Manag. 2006, 38, 388-410. [CrossRef] [PubMed]

18. Liu, D.W.; Richards, K. The He-Zhang (River chief/keeper) system: An innovation in China's water governance and management. Int. J. River Basin Manag. 2019, 17, 263-270. [CrossRef]

19. Chien, S.S.; Hong, D.L. River leaders in China: Party-state hierarchy and transboundary governance. Political Geogr. 2018, 62, 58-67. [CrossRef]

20. Wan, R.R.; Yao, X.; Yu, Z.H.; Dong, Y.W. Spatial and Temporal Variation of Water Quality of Typical Rivers in the River-Network Plain to the East of Tai Lake. Adv. Mater. Res. 2012, 518-523, 4253-4260. [CrossRef]

21. Yi, J.; Xu, F.; Gao, Y.; Xiang, L.; Mao, X.W. Variations of water quality of the major 22 inflow rivers since 2007 and impacts on Lake Taihu. J. Lake Sci. 2016, 28, 1167-1174.

22. Liu, X.X.; Chen, L. River Chief System: Breaking the water pollution control dilemma in China. Environ. Prot. 2009, 18-20. [CrossRef]

23. China Water Resources News. Modern River Chief Spreads to the Whole Country from Here: Investigation on the 10-Year Implementation of River Chief System in Wuxi, Jiangsu Province. Available online: http://www.chinawater.com.cn/ztgz/xwzt/2016hzz/7/201612/t20161213_453689.html (accessed on 15 February 2018). 
24. Jiang, B. Considerations for Leader Responsible System in governance of rivers and lakes. China Water Resour. 2016, 21, 6-7.

25. Wang, Y.; Mukherjee, M.; Wu, D.; Wu, X. Combating River Pollution in China and India: Policy Measures and Governance Challenges. Water Policy 2016, 18, 122-137. [CrossRef]

26. Ma, L.J. Civil River Chiefs become fresh troops for water management in Hangzhou. Policy Outlook 2016, 9 , $40-41$.

27. Ren, M. River Chief System: A sample study of inter-departmental coordination on watershed management in China. J. Beijing Adm. Coll. 2015, 25-31. [CrossRef]

28. People's Daily. Significant Achievements are Obtained after River Chief System Implemented on Main Rivers for Water Environmental Protection in Qujing, Yunnan Province. Available online: http://yn.people. com.cn/n2/2016/1014/c378439-29141633.html (accessed on 17 February 2018).

29. Dai, L.P. A new perspective on water governance in China: Captain of the River. Water Int. 2015, 40, 87-99. [CrossRef]

30. People's Daily. RCS Covers the Whole City in Wuxi, and Water Quality Gets Overall Improvement. Available online: http://wuxi.people.com.cn/n1/2016/1206/c131315-28927538.html (accessed on 17 February 2018).

31. China Daily. News Conference on the Guideline on Fully Implementing RCS. Available online: http://www.gov.cn/xinwen/2016-12/12/content_5146921.htm (accessed on 18 February 2018).

32. Zhang, Y.L. Can the contract system save rivers in China? Environ. Prot. 2009, 17-19. [CrossRef]

33. Fenjiang River Comprehensive Restoration Office (FRCRO). Study on Work Plan of Continuous and Further Improvement of Foshan Waterway; FRCRO: Foshan, China, 2011.

34. FRCRO. Reports on the Comprehensive Improvement Work of Fenjiang River in Foshan. Available online: http://www.fsswdx.gov.cn/tmp/201010/7.html (accessed on 22 February 2018).

35. Sun, Y.; Affilah, R.; Guo, J. Rethinking Chinese Campaign-Style Governance Model: The Case Study of APEC Blue. In Proceedings of the 2015 11th International Conference on Public Administration, Bandung, Indonesia, 9-11 December 2015; pp. 359-364.

36. Li, C.A.; Meng, X.X. Path of innovation of water environment governance model to long-term mechanism-Based on the "River Governor System". Urban Environ. Urban Ecol. 2015, 28, 34-38.

37. He, Q. "River Administrator" system from perspective of environmental law. Public Adm. Law 2011, 8, 78-82.

38. Wang, S.M.; Cai, M.M. Critique of the System of River-leader based on the perspective of new institutional economics. China Popul. Resour. Environ. 2011, 21, 8-13. 